\title{
The influence of primary infection date and establishment of vector populations on the spread of yellowing viruses in sugar beet
}

\author{
By W. VAN DER WERF, P. R. WESTERMAN, R. VERWEIJ and \\ D. PETERS \\ Wageningen Agricultural University, Department of Virology, P.O. Box 8045, \\ 6700 EM Wageningen, The Netherlands \\ (Accepted 27 January 1992)
}

\begin{abstract}
Summary
In three field experiments in 1985 and 1986, we studied the effect of the date of primary infection on the spread of beet yellows closterovirus (BYV) and beet mild yellowing luteovirus (BMYV) from artificially inoculated sugar beet plants. Laboratory-reared vector aphids, Myzus persicae, were placed on these sources of virus. There was no substantial natural immigration of vectors or viruses. In two experiments, one with BMYV in 1985 and the other in BYV in 1986 , populations of vector aphids remained low and there was little virus spread, i.e. c. 50 infected plants from one primarily infected source. The cause of this small amount of spread was the low number of vector aphids. In the third experiment, with BYV in 1986, large populations of $M$. persicae developed and there was substantial virus spread: c. 2000 infected plants in the plots which were inoculated before canopy closure. In later-inoculated plots in the same experiment, there was much less spread: $c$. 100 infected plants per virus source plant. Differences between fields in predator impact are implicated as the most probable factor causing differences in vector establishment and virus spread between these three experiments. Virus spread decreased with later inoculation in all three experiments.

A mathematical model of virus spread incorporating results from our work has been used to calculate how the initial proportion of infected plants in a crop affects the final virus incidence. This model takes into account the effect of predation on the development of the aphid populations. The processes underlying the spread and its timing are discussed.
\end{abstract}

Key words: Beet yellows closterovirus, beet mild yellowing luteovirus, green peach aphid, Myzus persicae, sugar beet, Beta vulgaris, virus spread, predators, coccinellids, mathematical model

\section{Introduction}

Virus yellows is a globally important disease of sugar-beet, Beta vulgaris ssp. saccharifera. Several studies (Russell, 1958, 1963, 1965; Björling \& Möllerström, 1974; Thielemann \& Nagi, 1977; Häni, 1979; Smith, 1986; Smith \& Hinckes, 1987) have shown that the disease (C) 1992 Association of Applied Biologists 
is in Europe most often caused by beet mild yellowing virus (BMYV, luteovirus group), but beet yellows virus (BYV, closterovirus group; Bar-Joseph, Garnsey \& Gonsalvez, 1979) is sometimes also important (Duffus, 1973). BMYV is transmitted in the persistent manner (Russell, 1962; Björling \& Nilsson, 1966) while BYV is transmitted in the semi-persistent manner (Sylvester, 1956; Bennett, 1960). Both viruses infect the leaves that are inoculated by the vector and the leaves that develop afterwards (Van der Werf, Bonnier \& Peters, 1989a). The infected leaves turn yellow, exhibit low rates of photosynthesis (Hall \& Loomis, $1972 a, b)$ and die prematurely. Under conditions of high temperature and high light intensity, BYV-infected leaves may develop additional symptoms like vein clearing and pinpoint or necrotic spots (Bennett, 1960; Björling, 1961, 1963). Yield loss per plant depends on the date of infection, the virus and sugar beet variety. Yield loss per ha depends also on the incidence of the disease. The maximum damage caused by BMYV is $c .35 \%$ while the maximum damage caused by BYV is c. 50\% (Watson, Watson \& Hull, 1946; Smith, 1986; Heijbroek, 1988; Smith \& Hallsworth, 1990).

Sugar beet yellowing viruses are not seed-borne (Duffus, 1973) and are introduced into the crops (primary infection) by immigrant aphids, often Myzus persicae. After primary infection, the viruses are disseminated in the crop by colonising aphids (secondary spread), of which the green peach aphid, M. persicae, is the most important vector (Watson, Hull, Blencowe \& Hamlyn, 1951; Björling, 1952; Heathcote, 1966, 1974). The black bean aphid, Aphis fabae, is a much less important vector of BYV. It was found unable to transmit BMYV in early studies (Russell, 1963; Björling \& Nilsson, 1966) while later experiments by Thielemann \& Nagi (1979) and Karl \& Giersemehl (1981) showed that some strains of $A$. fabae do transmit BMYV, although not efficiently. The population dynamics of $M$. persicae and the spread of beet yellowing viruses have been studied in the field by several authors (Björling, Lihnell \& Ossiannilsson, 1951; Björling, 1952; Watson \& Healy, 1953; Ribbands, 1963; Kershaw, 1965; Watson \& Heathcote, 1966). Barel (1975) and Thresh (1983) provided evidence that the number and earliness of primary infections are important determinants of the final level of infection of the beet crop that results from the initial infection and secondary spread. The Dutch warning scheme for virus yellows in sugar beet accounts for the lesser importance of later infections, by raising the warning threshold of $M$. persicae as the crops grows. Thus, in May, spraying is advised with one aphid per five plants, while in July, when the canopy is closed, five aphids per plant are tolerated (Barel \& Dudok van Heel, 1978; Heijbroek, 1984). However, warning schemes in other European countries have fixed thresholds (Dewar, 1988).

More knowledge about the processes underlying the spread and its timing is needed to underpin flexible warning thresholds for the vector aphids. To acquire such knowledge, we conducted three field studies on the spread of BYV and BMYV from artificially inoculated sources, infected at different times during the season. The results of these studies are presented here and their implications for warning thresholds are quantitatively analysed with a simple mathematical model.

\section{Materials and Methods}

\section{Layout of experiments}

Three field-experiments were made. Expt 1 examined the spread of BMYV in 1985, Expts 2 and 3 examined the spread of BYV at two locations in 1986. Expts 1 and 2 were done on a river clay type soil at an experimental farm at Randwijk (near Wageningen). Expt 3 was done on a sea clay type soil at the Wageningen Agricultural University farm 
near Swifterbant, $100 \mathrm{~km}$ from Wageningen. Sugar beet varieties 'Regina' (Expts 1 and 3) and 'Bingo' (Expt 2) were used. The crops were sown between 18 and 25 April at a row distance of $50 \mathrm{~cm}$ and a final plant density of about seven to nine plants $\mathrm{m}^{-2}$ (varying from field to field and within fields). The experiments were laid down as randomised block designs with six replicates. Plot size was $12 \mathrm{~m} \times 12 \mathrm{~m}$. Each experimental block contained at least one control plot in which observations were made on immigrant aphids and viruses.

\section{Inoculations}

Viruses were maintained in sugar beet in aphid-proof greenhouses as described by Van der Werf, Kempenaar \& Peters (1989b). We used a severe BYV isolate that causes vein clearing and necrotic spots under suitable conditions. The BMYV isolate used was also severe, causing clear yellowing, orange discolorations and necrotic symptoms in plants grown at high light intensities. Inoculations with virus were made at 7 or 10 day intervals by placing aphid-proof clip-cages containing 10 to 30 viruliferous $M$. persicae on one or three central plants per plot (see below). Three cages per plant were used. To prevent viruliferous aphids escaping, the standard type of clip-cage described by Adams \& van Emden (1972) was modified by putting gauze on both sides, so that aphids had to feed through the gauze to reach the leaf. The aphids were introduced through the sidewall of the cage via a hole that was subsequently sealed. Viruliferous aphids were collected as described by Van der Werf et al. (1989b).

In Expt 1, inoculations were made on 23 and 30 May and on 6, 13, 20 and 27 June. One central plant per plot was inoculated. All plants became infected following inoculations on 6 and 13 May, only two plots became infected after inoculation on 20 June and no plants became infected after other inoculations. In Expt 2, three central plants per plot were inoculated with BYV on 9, 19 and 29 June and 9 July and all plants became infected. In Expt 3, inoculations with BYV were made on 20 and 30 May, on 10, 20 and 30 June, and on 10 July. Three central plants per plot were inoculated and all plants became infected. A number of plots had to be discarded because glyphosate herbicide killed one or more inoculated plants or created large gaps in the plots.

\section{Initial infestation with $\mathrm{M}$. persicae}

In all experiments, non-viruliferous $M$. persicae were introduced on the central plants to initiate the build-up of vector colonies on the virus-source plants. The Wageningen M3 clone was used throughout (Reinink, Dieleman, Jansen \& Montenarie, 1989). In Expt 1, a wingless young adult $M$. persicae was clip-caged onto the central plant once a week, using a standard aphid clip-cage (Adams \& van Emden, 1972), from the day after the inoculation until 28 June. In Expt 2, five wingless young adult $M$. persicae were clip-caged on each of three central plants from 13 to 16 June. Extra introductions were made on plants adjacent to the central plants on 29 June (five adults/plot) and 9 July (seven adults/plot) in plots where colonisation by $M$. persicae was poor. $M$. persicae were also introduced in six control plots in which no virus was inoculated. In Expt 3, each central plant, including those in uninoculated control plots, received a clip-cage with three wingless young adult $M$. persicae on 20 May. The $M$. persicae were also introduced in six extra control plots in which no virus was inoculated.

\section{Aphid monitoring}

M. persicae were monitored weekly or fortnightly from the initial infestation until the numbers were negligible in August or September. All leaves on a sample plant were turned 
and examined. The occurrence of predators, parasites, parasitic fungi or other aphid species was noted. Counts were made in each plot on the central plant(s) on which aphids were introduced, on three sample plants at distances of $c .0 .5,1.0$ and $1.5 \mathrm{~m}$ within the row of the central plant(s) and on three plants at distances of $c .0 .5,1.0$ and $1.5 \mathrm{~m}$ across rows. Aphids were classified as L1-L3, apterous L4 (without wing pads), alatiform L4 (characterised by wing pads, elongated shape and in the M3 clone also by a red body colour), apterous adult or alate adult ( $\mathrm{L}$ stands for larval instar).

\section{Assessments of virus spread}

Plants showing obvious systemic symptoms were counted weekly and marked with bamboo sticks until September/October when no more plants developed symptoms. The delay from inoculation to the appearance of systemic symptoms (incubation period) was determined in a separate part of each field by inoculating batches of $c .30$ plants at regular intervals and monitoring the symptoms weekly. In Expt 3, the monitoring of visible disease progress by individual plant counts was stopped after 7 August because the rapid spread rendered the procedure impracticable. A final estimate of the number of infected plants in Expt 3 was made on 15 October by measuring the diameters of the patches.

\section{Results}

Summary of results of the three experiments

In Expts 1 (BMYV) and 2 (BYV), small patches containing 10-50 virus-infected plants developed (Fig. 1A). The largest patches were obtained with early inoculation. Few $M$. persicae were found (maximum of $c$. four per plant; Fig. 1B). In Expt 3, large patches of

Final number of yellowed plants

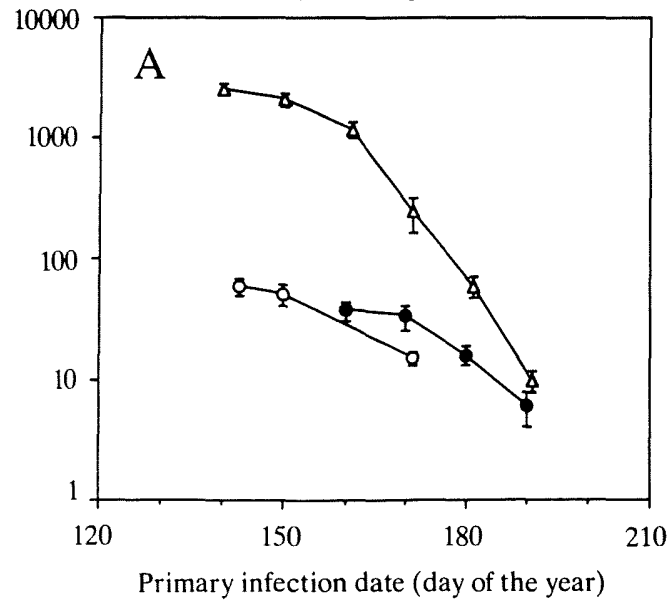

Peak number of Myzus persicae per sample plant

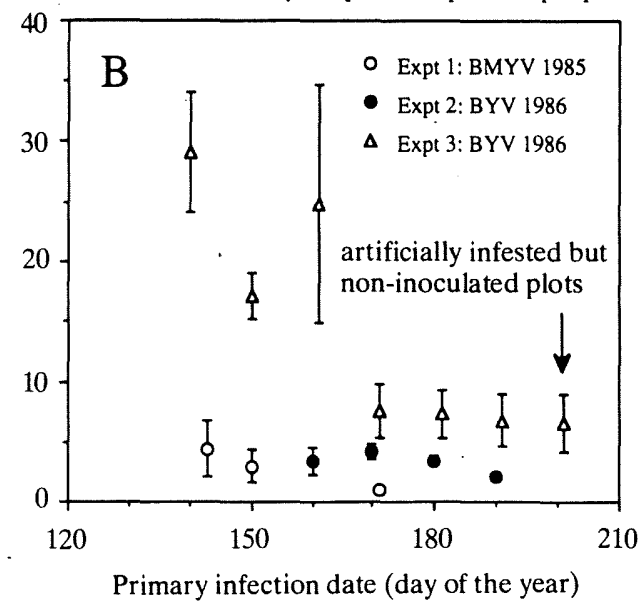

Fig. 1. Comparison of virus spread and number of $M$. persicae in three sugar beet field experiments on the influence of primary infection date with yellowing viruses. A: Final number of infected plants per plot as a function of infection date. B: Number of $M$. persicae at the peak (Expts 1 and 2) or shortly thereafter (Expt 3) as a function of infection date. Bars denote standard error of the mean (SEM). The time-axis (abscissa) is divided in 30 day-periods that correspond approximately to the months May, June and July. 1 January is day number 1; 1 May is day $121 ; 1$ June is day $152 ; 1$ July is day 182 and 1 August is day 213. 
c. 2000 BYV-infected plants developed in early-inoculated plots (Fig. 1A). The number of infected plants decreased substantially with later inoculation to negligible levels in the plots inoculated on 10 July: $c$. 10 infected plants. Many $M$. persicae were found, up to $c$. 70 per sample plant (Fig. 1B). The observations in the control plots in the three experiments (data not shown) indicated that natural vector and virus pressure were low and can be neglected. A detailed presentation of results in each experiment is given below.

\section{Experiment 1: BMYV: 1985}

\section{Virus spread}

There was little spread of BMYV in Expt 1 and few M. persicae developed on the sample plants. The final number of infected plants counted on 20 September was $59 \pm 10$ (s.E.M.) in the six plots inoculated on 23 May, $52 \pm 11$ in the six plots inoculated on 30 May, and $15 \pm 2$ in the two plots infected on 20 June. Thus, the last inoculation resulted in less spread than the two early inoculations. Most infected plants developed symptoms in August (Fig. 2; quadrant III). The curves of infection progress (Fig. 2; quadrant I) are derived by projecting the observation data backwards in time with the incubation period of the symptoms (Fig. 2; quadrant II). The curves in quadrant I indicate that the first secondary infections were made in June while most secondary infections were made in July.

\section{Population dynamics of aphids and predators}

Fig. 3 shows the population development of the vectors, M. persicae, A. fabae, and coccinellids, which constituted the most numerous group of predators. There were more $M$. persicae in the plots inoculated on 23 and 30 May than in those inoculated on 20 June. The numbers of $M$. persicae increased after their introduction and declined at the end of July. The $A$. fabae population also declined substantially in the last 10 days of June (Fig. $3 \mathrm{~A}) .30 \%$ of the plants were infested with coccinellids (mostly Coccinella septempunctata) at the time both aphid populations declined (Fig. 3B). Predation probably contributed significantly to aphid mortality. There was no correlation between the occurrence of $A$. fabae and the spread of BMYV.

Experiment 2:BYV:1986

\section{Virus spread}

Little virus spread occurred in the second experiment (Fig. 4). The final number of BYVinfected plants, counted on 6 October was $38 \pm 7$ in the plots inoculated on 9 June, $34 \pm$ 8 in the plots inoculated on 19 June, $16 \pm 3$ in the plots inoculated on 29 June and $6 \pm 2$ in the plots inoculated on 9 July. Thus, the extent of secondary infection decreased significantly with later inoculation. The number of plants with virus symptoms increased throughout July and August (Fig. 4; quadrant III) while most of the secondary infections were made in the second half of June and the first half of July (Fig. 4; quadrant I). The initial few secondary infections were made at the end of June in the plots inoculated on 9 and 19 June and in the second 10 days of July in the plots inoculated on 29 June and 9 July.

\section{Population dynamics of aphids and predators}

The $M$. persicae, introduced on 13 June, started small colonies on the sample plants. These populations declined substantially in the middle of July. The number of $M$. persicae was similar in the four treatments, although there was a slight tendency for more $M$. persicae 
Number of infected plants
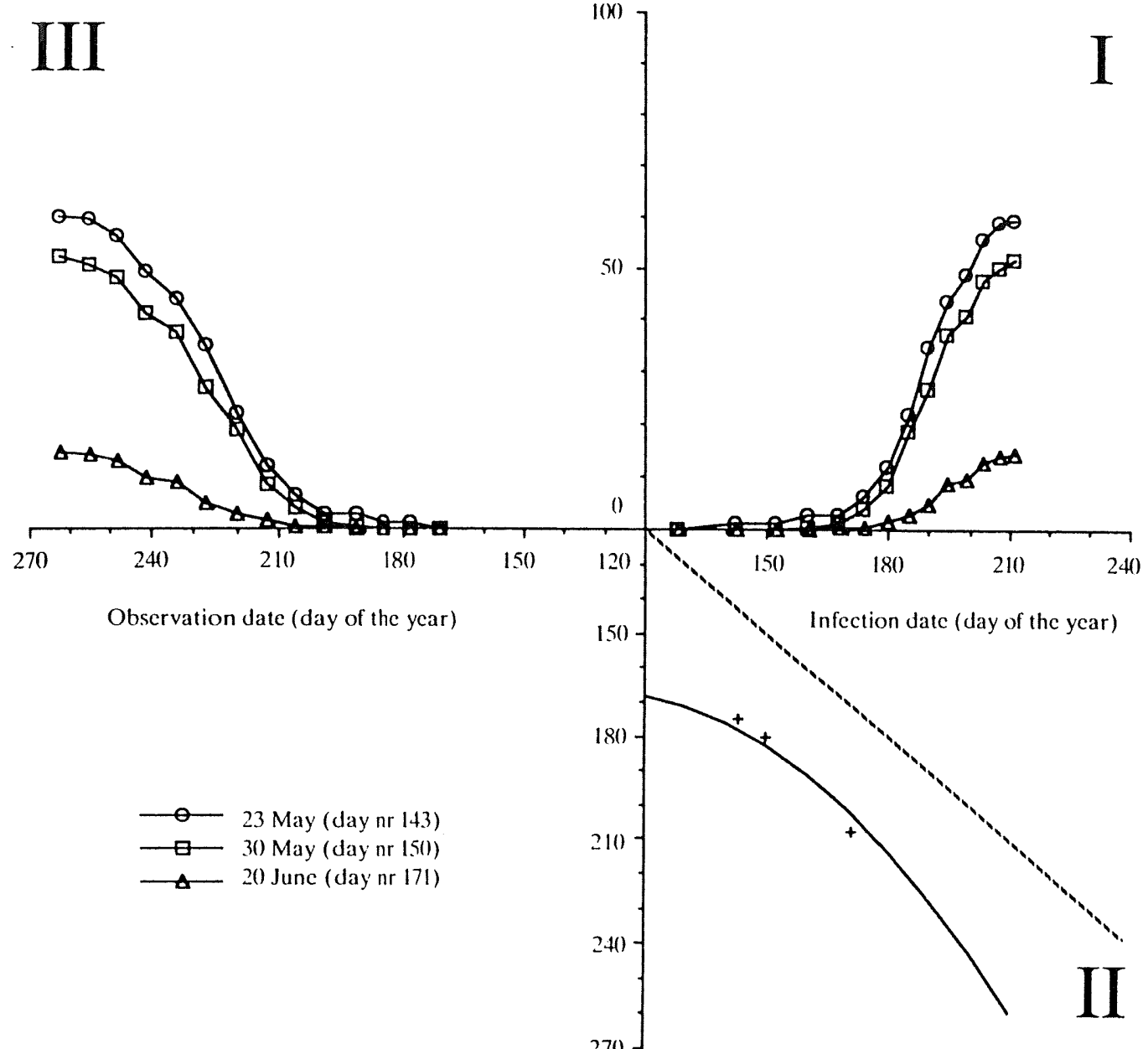

Obscrvation datc (day of the ycar)

Fig. 2. Temporal analysis of virus spread in Expt 1: BMYV, 1985. Quadrant I, upper right-hand corner, shows reconstructed curves of infection progress. These curves are derived from progress curves of the number of plants with symptoms as shown in the upper left-hand quadrant III. The translation from the observation time-axis to the infection time-axis is made with a curvilinear regression line relating the date of symptom observation to the date of infection, shown in the lower right-hand quadrant II. The equation describing the line is: $t_{\mathrm{i}}=107+10.7 \sqrt{t_{\mathrm{o}}-167}$, where $t_{\mathrm{i}}$ is the estimated day of infection and $t_{\sigma}$ is the day of symptom observation (Van der Werf et al., 1989b). Time is again expressed as day of the year. The regression line is based on observations of the incubation period of BMYV made in a number of fields in the Netherlands in 1984, 1985 and 1986. Observations made in the present experiment 1 are indicated with + . The increase of the incubation period during the season causes the infection time-axis to be compressed as compared to the observation time-axis.

to develop in earlier inoculated plots (Fig. 5A). The number of coccinellids (mostly Propylea quatuordecimpunctata) was not high, but they were present from the date of introduction of $M$. persicae and may therefore have had a profound influence on the establishment of $M$. persicae. We noted aggregation of coccinellids at cages with introduced aphids. A. fabae occurred at low densities. 

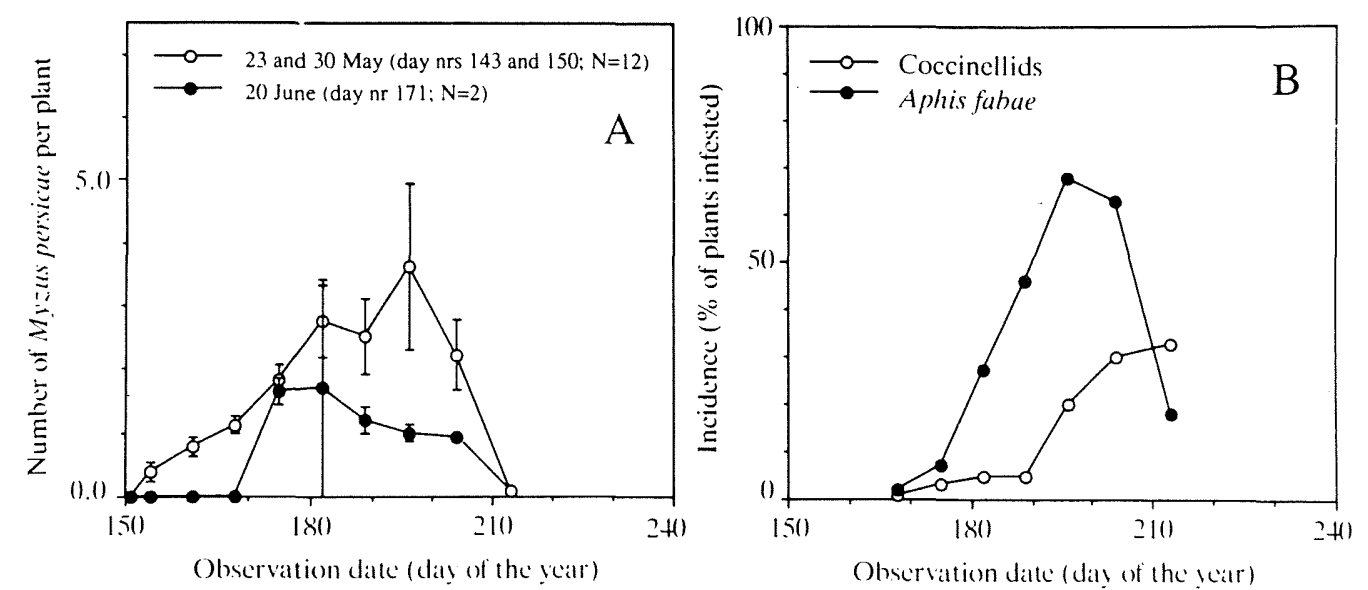

Fig. 3. Population dynamics of $M$. persicae (A), A. fabae and coccinellids, predominantly $C$. septempunctata (B) in Expt 1: BMYV, 1985. Consistently similar counts of $M$. persicae in the plots inoculated on 23 and 30 May are averaged in the figure. Bars denote standard error of the mean (SEM). Incidence counts (B) are given for all plots together and are therefore given without standard error.

Experiment $3: B Y V: 1986$

Virus spread

Expt 3 differed from Expts 1 and 2 in that much more virus spread occurred. This was especially the case in the plots inoculated on 20 or 30 May or 10 June, which will be referred to as 'early-inoculated plots' in the following. In the later-inoculated plots, i.e. those inoculated on 20 or 30 June or 10 July, much less spread occurred (Fig. 6).

The time-course of virus spread in early- and late-inoculated plots is significantly different (Fig. 6; quadrants I and III). In the early-inoculated plots, the dissemination of virus started in late June and the first week of July, while in the late-inoculated plots no dissemination took place before the second week of July. In the early-inoculated plots, virus was rapidly spread after 10 July, while the rate of spread was then modest or low in the late-inoculated plots. Symptoms developed at the end of July in the early-inoculated plots while large yellow patches became visible during August. Patches in the early stages of development did not appear in the late-inoculated plots until the beginning of September. The final outcome was that $c .2000$ plants became infected in the early-inoculated plots, while the number of infected plants in the late-inoculated plots was one or two orders of magnitude lower (Figs 1 and 6). These observations suggest that the crop passed a critical development stage between 10 and 20 June, after which primary virus infections did not result in early and extensive virus spread.

\section{Population dynamics and dispersal of aphids and population dynamics of predators}

Significantly more $M$. persicae developed in early-inoculated plots than in late- or notinoculated ones (Fig. 7), although an equal number of aphids was introduced in all plots on 20 May. The number of $M$. persicae in the late-inoculated plots was not significantly different from the number in the six virus-free control plots which had been artificially infested. 


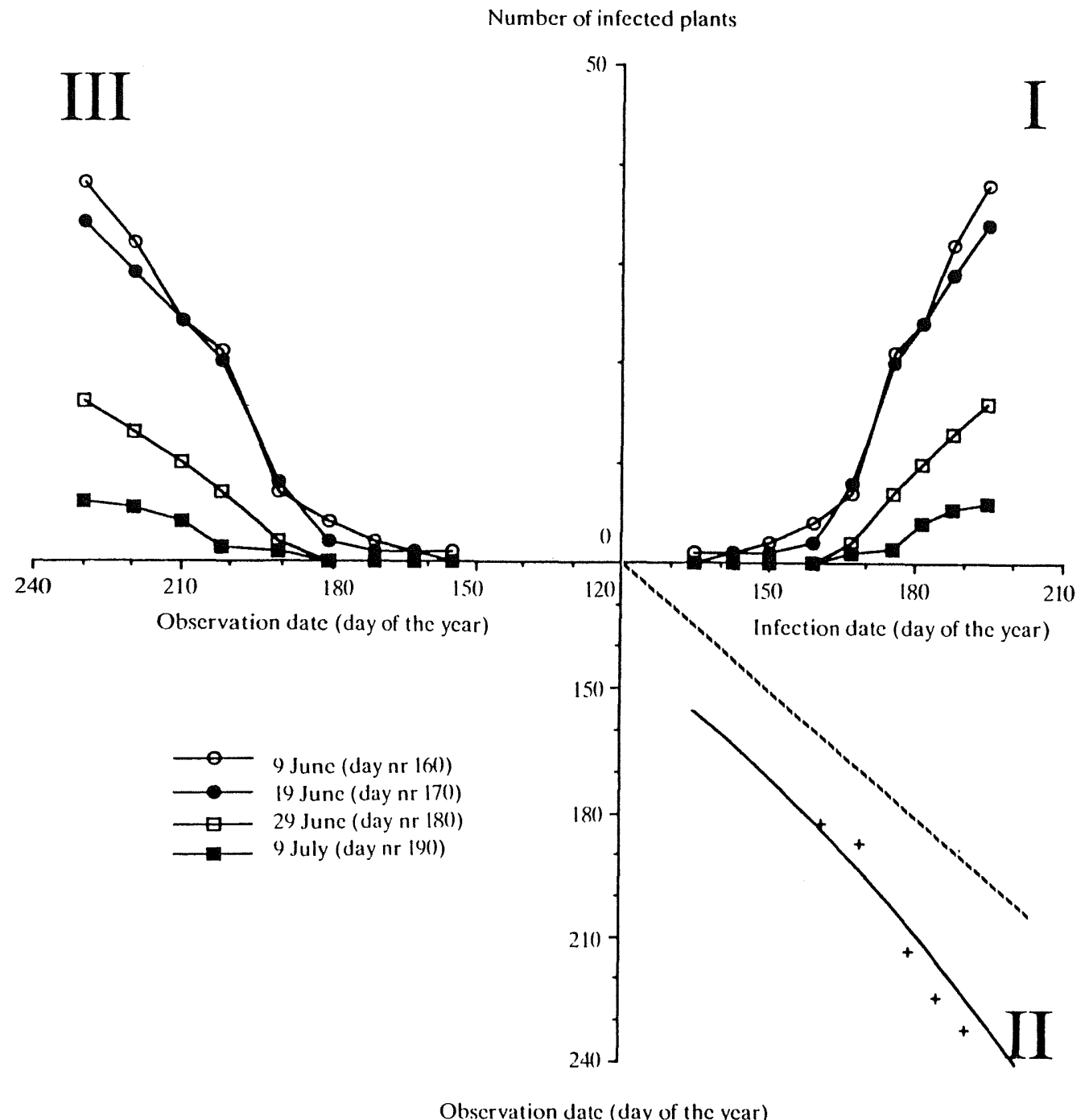

Fig. 4. Virus spread in Expt 2: BYV, 1986. Curves of visible disease progress are shown in upper lefthand quadrant III, while the reconstructed curves of infection progress are shown in upper right-hand quadrant $I$. The equation defining the translation from date of symptom expression to infection date in quadrant II is: $t_{\mathrm{i}}=35+14.4 \sqrt{t_{\mathrm{o}}-107}$, where $t_{\mathrm{i}}$ is the estimated day of infection and $t_{\mathrm{o}}$ is the day of symptom observation (Van der Werf et al., 1989b). Time is expressed as day of the year. The regression line is based on observations of the incubation period of BYV made in a number of fields in the Netherlands in 1984, 1985 and 1986. Observations made in this experiment are indicated with + .

The differences in virus dissemination resulting from inoculations made before and after 15 June are explained by the observations of aphid dispersal: on 26 May, 3 days after removal of the clip-cages, aphids were found only on the central plants, not on any neighbours. On 4 June, aphids occurred on $50 \%$ of the adjacent plants within the row, and on 11 June they were found on most immediate neighbours and also on some plants at a distance of $1 \mathrm{~m}$. On 20 June, when the leaves of plants in adjacent rows had started to touch, aphids were found on virtually all sampled plants. We think that the formation of 

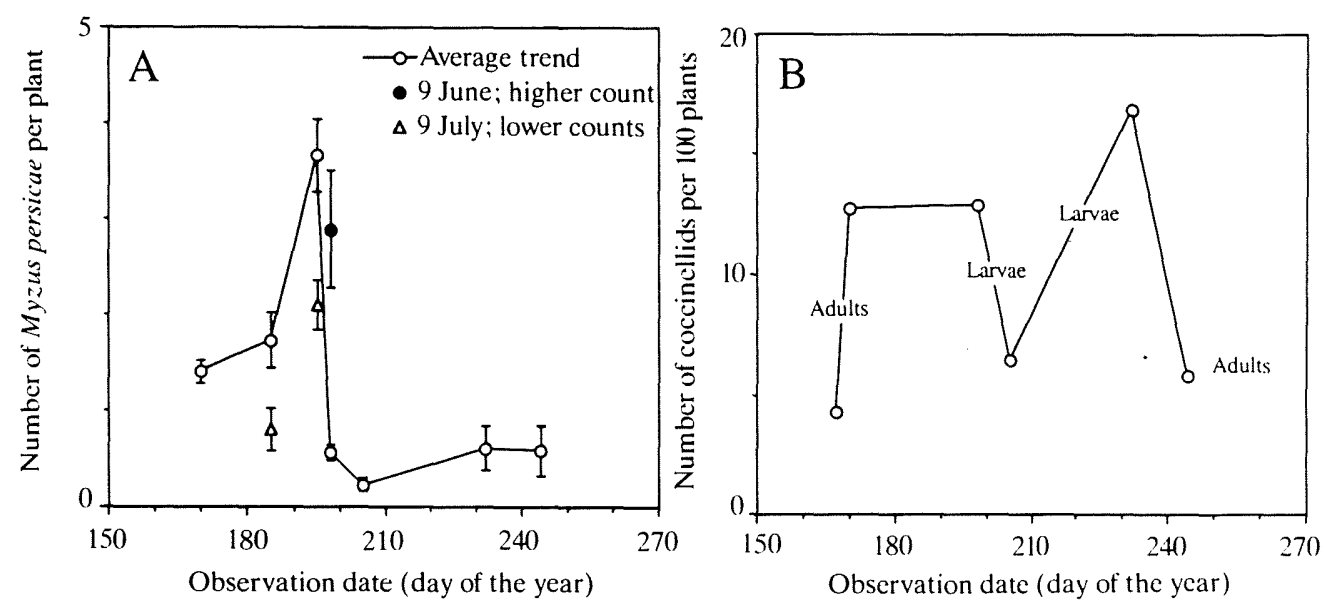

Fig. 5. Monitoring data of $M$. persicae and coccinellids in Expt 2: BYV. 1986. (A) Average number of M. persicae per sample plant. Bars denote standard error of the mean (SEM). Except for three significant differences denoted in the figure, the four treatments had similar numbers of aphids and an average is presented in the figure. The first inoculated plots ( 9 June) had a significantly lower count than the other plots on 17 July, while the last inoculated plots ( 9 July) had significantly higher counts on 4 and 14 July. These points are presented separately. (B) Coccinellids; predominantly P. quatuordecimpunctata.

'leaf bridges' between plants in the period between 10 and 20 June facilitated inter-plant movements of aphids, thus increasing the dispersal of the aphids. This timing of aphid dispersal is in good agreement with the estimated start of virus spread, as shown in Fig. 6 , the first quadrant. It also provides an explanation for the sharp distinction between earlyand late-inoculated plots. In the early-inoculated plots, the dispersing aphids spread virus, but when the aphids in the late-inoculated plots dispersed after 15 June, the plants were not yet inoculated.

Aphid dispersal must have spanned distances of at least $10 \mathrm{~m}$ to cause patches of the size observed. Both wingless and winged aphid forms may have contributed to the spread. The quite low number of winged nymphs and adults during the second half of June (Fig. 7C,D) indicate that the initial spread was caused mainly by apterae. Winged aphids may have played a greater role during July, especially in the early-inoculated plots in which the majority of nymphs developed wing pads (Fig. 7C). The low number of winged adults on the sample plants as compared to the number of nymphs with wing pads (Figs $7 \mathrm{C}$ and $\mathrm{D}$ ) indicates, however, that most winged aphids left the sample area soon after moulting, thereby spreading virus outside it. Whether they left the plot or field, or made a contribution to the patchwise virus spread cannot be deduced from the observations with certainty.

The low numbers of coccinellids observed before the population peak of $M$. persicae did not prevent the aphids building up high densities in the early-inoculated plots. Coccinellids (mostly $C$. septempunctata) reached higher incidences during and after the aphid peak, at the end of June.

\section{Implications of experimental results for damage thresholds}

By some elementary calculations, it can be shown what the results imply for the number of primary infections that could be tolerated in a sugar beet crop. We thereby assume that the results of Expts 1 and 2 represent situations in which predators are effective in controlling aphids and virus spread while the results of Expt 3 represent situations in which predators 
Number of infected plants
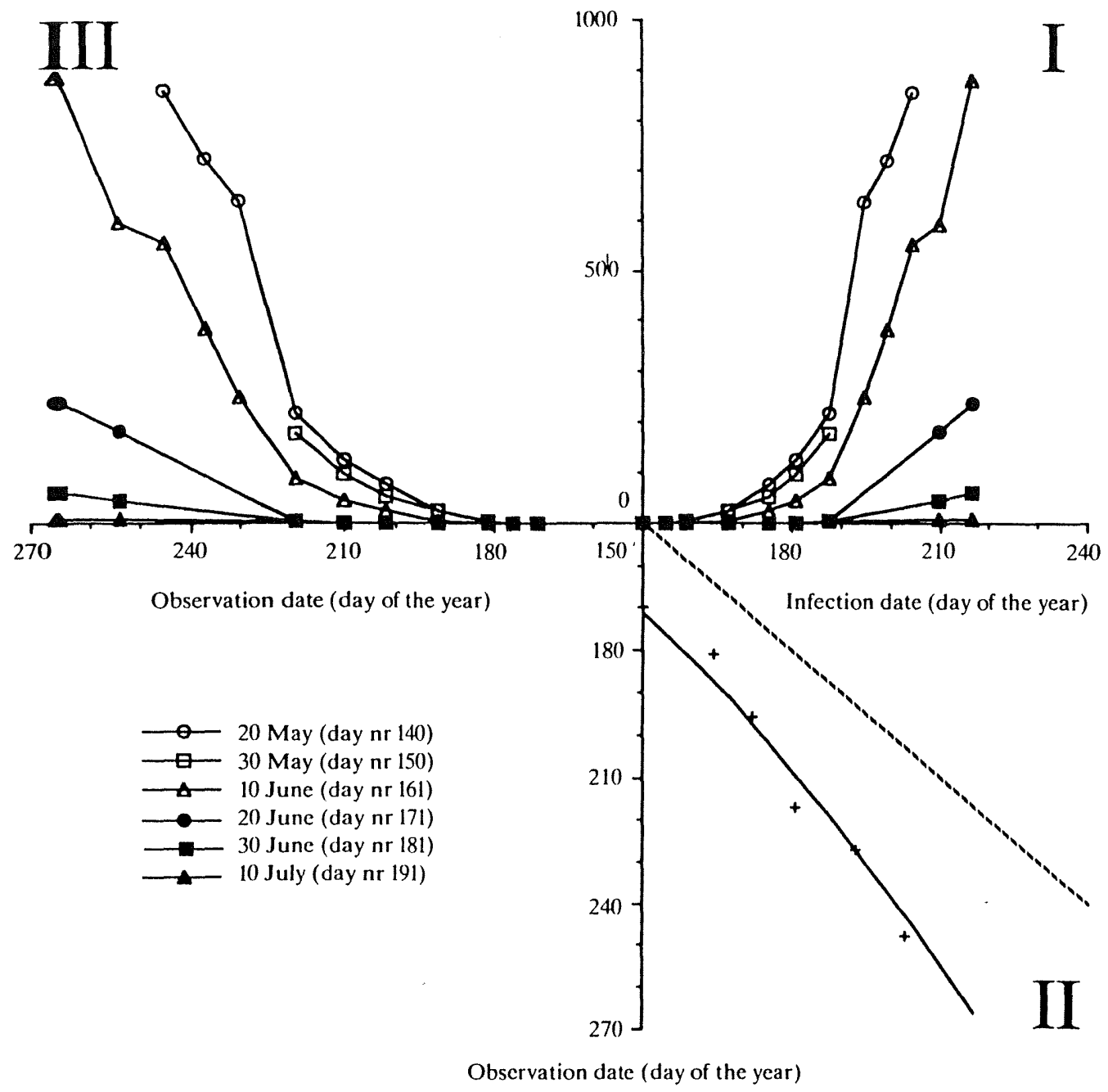

Fig. 6. Virus spread in Expt 3: BYV, 1986. Curves of visible disease progress are shown in upper lefthand quadrant III, while the reconstructed curves of infection progress are shown in upper right-hand quadrant $\mathrm{I}$. The equation defining the translation from date of symptom expression to infection date is the same as in Fig. 4. For more explanation of the method of presentation, $c f$. Fig. 2.

are ineffective. Further, we assume that all primary infections are made simultaneously, that each of them results in a patch, that all patches are of the same size, and that the size of the patches is a function of primary infection date, as described by our experimental results. For this purpose, the experimentally derived relations between infection date and focus size (Fig. 1A) are summarised with two regression equations (see Appendix). One equation describes the Expts 1 and 2, that were not conducive to virus spread, and another equation describes the situation in Expt 3 that was very conducive to virus spread. Overlap between patches is taken into account by the model. The final incidence of virus yellows serves as a rough criterion for damage. The model does not go into details of sugar and pesticide prices, as these may change rapidly and invalidate the calculations. Fig. 8 gives 

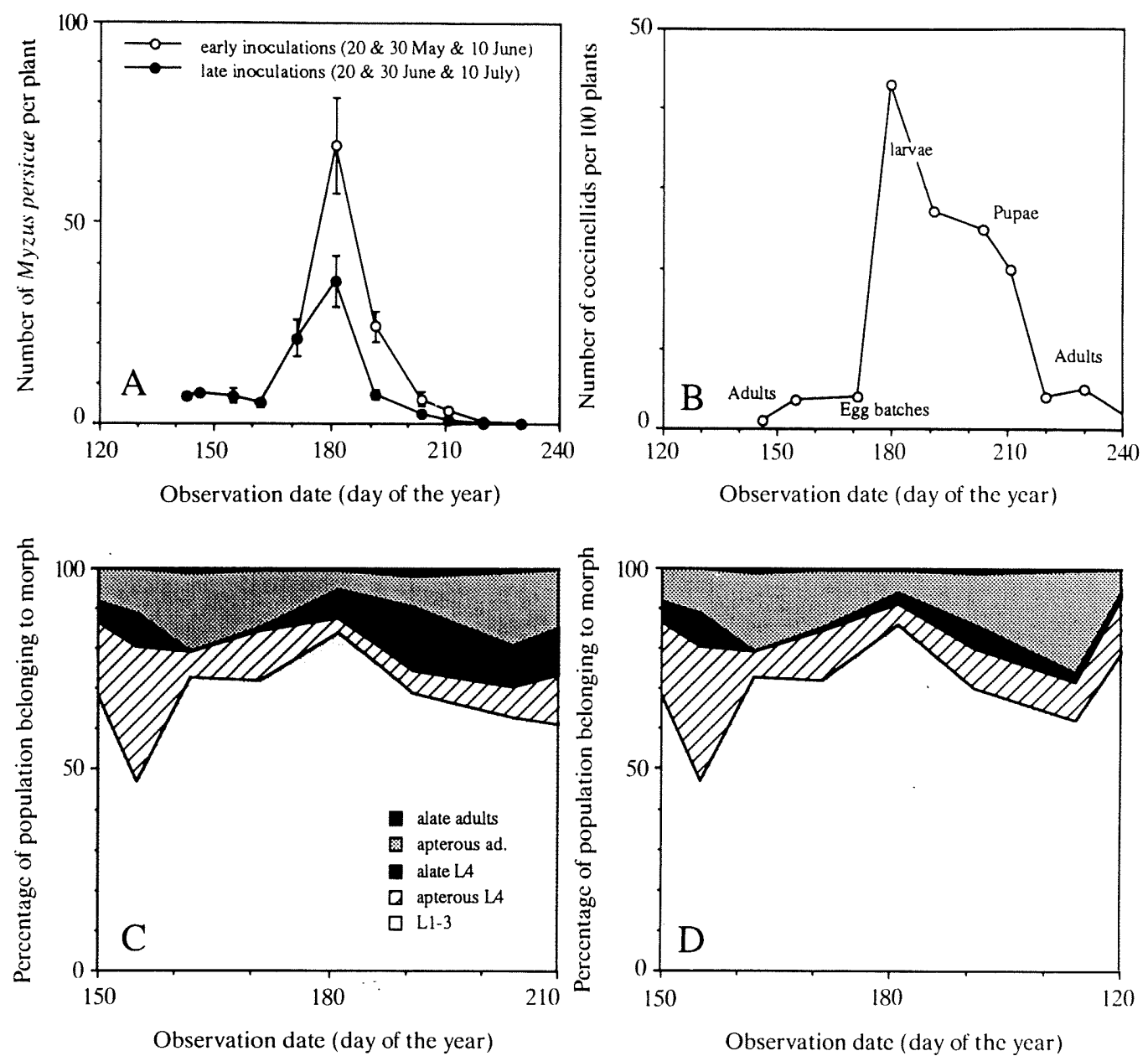

Fig. 7. Monitoring data of $M$. persicae and coccinellids in Expt 3: BYV, 1986. (A) Average number of $M$. persicae per sample plant \pm SEM. Data for early-inoculated plots (three different inoculation dates) and those for late-inoculated plots (three inoculation dates) were analysed as groups because the counts were not significantly different within groups. (B) Coccinellids; predominantly $C$. septempunctata. (C) Morph composition of $M$. persicae population in early-inoculated plots. (D) Morph composition in lateinoculated plots.

the number of primary infections per ha of crop that will yield a specified incidence of yellows, based on the date of the primary infections and the conduciveness of the field to secondary virus spread.

The curves presented in Fig. 8 show that, when the field is not conducive, as in Expts 1 and 2, many primary infections can be sustained, while extremely few early primary infections can be tolerated when the field is conducive to secondary virus spread, as in Expt 3.

\section{Discussion}

The three experiments described in this paper suggest that the spread of beet yellows virus and beet mild yellowing virus in sugar beet occurs in three phases. 


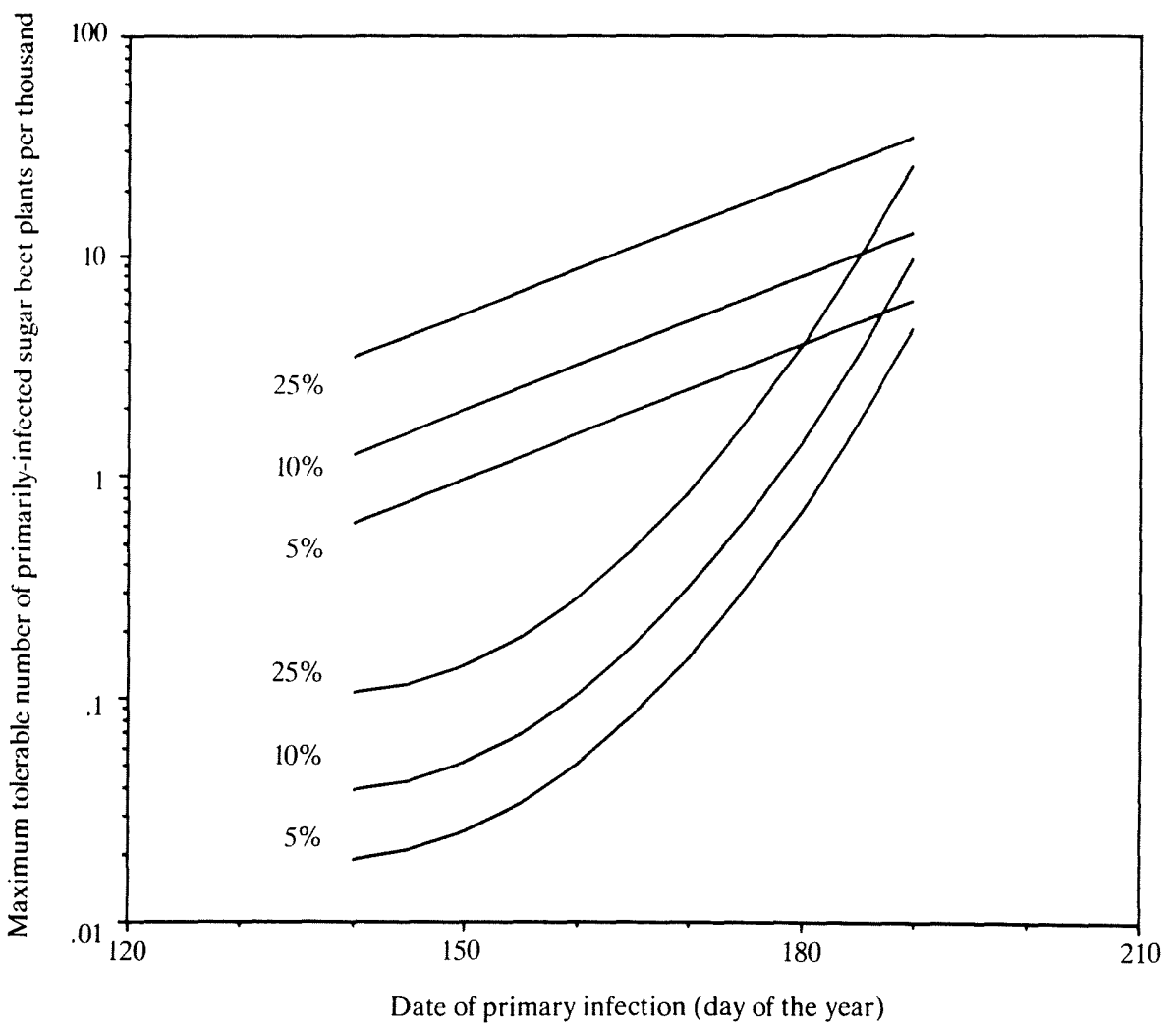

Fig. 8. Incidence of primary infections of beet yellowing viruses, giving specified incidences of disease $(5 \%, 10 \%$ or $25 \%)$ in fields that are conducive to virus spread (lower three curves) and in fields that are not (upper three curves) as a function of infection date. The calculations (see text and Appendix) assume that all primary infections are made simultaneously, that each primary infection initiates a single focus of yellows, and that the relation between size of the focus and the date of primary infection can be summarised by two regression equations (Eqns 3 and 4) fitted through field data presented in Fig. $1 \mathrm{~A}$.

1. Introduction phase. The introduction phase starts when seedlings emerge and ends when the plants make leaf contact. During this phase, vectors and viruses enter the crop and start their multiplication, but little dispersal occurs. If no viruliferous vectors enter the crop, or if these are destroyed by natural enemies, there will be no basis for extensive secondary spread.

2. Establishment phase. When the plants make leaf contact (typically mid-June), dispersal of the aphids becomes easier, such that secondary virus spread can begin. Little spread occurs initially, however, because the aphids have no incentive for dispersal as long as the plants are good hosts, aphid density is low and predators are low in number. Because aphids and viruses multiply quickly when the plants are young, a reservoir of infectious plants and aphids can be built up during this period. $M$. persicae and beet yellowing viruses have a mutual benefit from each other's presence, as the aphid spreads the virus while infection with virus renders the plants more suitable as a food source for the aphid (Baker, 1960; Williams, 1986). Because of the positive feedback involved in this relationship between virus and vector, a slightly earlier introduction of virus and vectors may strongly increase the size of the reservoir. 
3. Dissemination phase. Decreasing host suitability of the plants is probably a major cause of dispersal during the dissemination phase, but increasing disturbance by natural enemies (Frazer, 1977; Roitberg, Myers \& Frazer, 1979) and increasing aphid density, causing mutual disturbance, may also play a role (Dixon, 1985). The risk of extensive dissemination of the virus is greatest when an important reservoir of infectious plants and aphids has been built up during the establishment phase. This happened in the early-inoculated plots in Expt 3 .

Distinguishing such phases of spread may help to explain the effects of natural enemies or pesticides on the spread of viruses. Natural enemies and pesticides are more likely to be effective in the introduction phase or the early establishment phase than in the late establishment and dissemination phase, when they may have a deleterious effect, increasing vector restlessness and dispersal ( $c f$. Rice, Gibson \& Stribley, 1983a,b), in addition to their beneficial effects of killing the vectors. After the dissemination phase, ending in the middle of July, control measures are not effective.

In Expt 3, more $M$. persicae were counted in the early-inoculated plots than in the lateor un-inoculated ones. The favourable effect of BYV infection on the survival and rate of reproduction of $M$. persicae on sugar beet (Baker, 1960; Williams, 1986) is the most feasible explanation for this observation. There is also a possibility that the infected plants in the early-inoculated plots lured $M$. persicae, as yellow is an attractive colour to this aphid (Moericke, 1955, 1957). However, there are two arguments against this explanation: (1) most naturally occurring $M$. persicae in the Netherlands are green, while most individuals counted in the plots were yellow, confirming their descendence from the originally introduced M3-clone individuals; (2) the aphid populations declined substantially at the end of June, when the yellow patches were just starting to develop. There was also a difference in morph composition between the $M$. persicae populations in the early- and in the lateinoculated plots (Figs 7C and D). The populations in the early-inoculated plots had a higher proportion of winged nymphs. This increased proportion of winged nymphs might be a direct result of the different nutritional status of BYV-infected sugar beet plants. It might also be thought to result from the higher aphid densities that occurred on the infected plants. Such high densities generally promote wing development in aphids. A similar effect of virus infection of the host plant on aphid morph determination was observed by Gildow (1980) in barley yellow dwarf virus-infected oats. The effects of BYV on the population development and morph determination of $M$. persicae on the sugar beet promote the spread and long-term survival of the virus in the agro-ecosystem.

The poor establishment of $M$. persicae in Expts 1 and 2 and the good establishment in Expt 3 reflect differences in the life history of these aphids in these respective fields; i.e. greater and/or earlier reproduction in Expt 3 or smaller and/or later mortality. The rates of production of nymphs by the initially introduced adults were virtually the same in the three experiments: 2.1 to 2.3 nymphs per mother per day. Thus, there are no indications for differences in host plant quality between the fields. Differences in predator activity offer an explanation for differential establishment. Entwistle \& Dixon (1989) showed that individual cereal fields differ significantly with respect to predator activity and suitability for cereal aphid multiplication. Evidence that the same is true for sugar beet was obtained by Hodek, Novák, Skuhravy \& Holman (1965) and by Hodek (1966). These authors found that $C$. septempunctata could prevent $A$. fabae from establishing colonies in sugar beet under natural conditions. In field cages, they observed that such interference of the ladybirds with aphid establishment occurred in two seasons when the ratio of aphids to coccinellids was 70 or less. At higher aphid-coccinellid ratios, up to 200, predation was effective only in the warmest of the two seasons. Such observations are in agreement with ours. In Expts 1 and 2, the ratio of $M$. persicae to coccinellids in late June was always less than 100 (Figs 
3 and 5) whereas in Expt 3, ratios greater than 200 occurred (Fig. 7). Thus, the early introduction with significant numbers in Expt 3 may have caused the aphid colonies to be large enough to compensate for predation by the time predators became active. In Expt 1, the introductions were made with smaller numbers and in Expt 2 at a later stage of the season. However, this explanation is only indicative, as aphid species, age of the crop, morph structure of the aphid population, weather and other predator groups are not taken into account.

Coccinellids have been mentioned as significant predators of virus-transmitting aphids in sugar beet by more investigators. Heathcote $(1963,1978)$ asserted that foraging coccinellids can prevent immigrant aphids from establishing colonies. Ribbands (1963) observed that coccinellids reduced the number of $M$. persicae in virus-infected sugar beet. Wratten \& Pearson (1982) and Putman \& Wratten (1984; p. 257) report that predator exclusion from sugar beet plots increased numbers of aphids as well as the incidence of beet western yellows virus. Our experiments provide new evidence that predators are able to prevent or reduce virus spread in crops if they occur at the right time to affect the population dynamics of vectors. This activity of predators may be widespread but is not well recognised and it is not likely to be used well in current agricultural practice.

The alternative virus vector $A$. fabae was abundant in Expt 1. Our observations do not indicate that it played a role as virus vector, which is in accordance with previous work by Watson et al. (1951), Björling (1952) and D. Peters (unpublished results). We think that $A$. fabae may play an indirect and more important role in virus spread by providing alternative food for predators that can affect the spread of virus by attacking $M$. persicae.

The severe beet yellows outbreak in Europe in 1974 was initiated by early and numerous primary infections (Barel, 1975; Heijbroek, 1984) while secondary spread started early (Hull, 1975; Thresh, 1983). Because symptoms of beet yellowing viruses develop after long incubation periods (Van der Werf et al., 1989b), it is not possible to base spray warnings on the observation of symptoms. Forecasts with weather-based regression equations (Watson, Heathcote, Laukner \& Sowray 1975; Harrington, Dewar \& George, 1989) enable a more timely prediction to be made of when control measures should be used. These regressionbased predictions take into account the survival of virus and vectors through the winter and the earliness of aphid flights and primary infections. However, these predictions are not always accurate (Heathcote, 1986) and they cannot take account of field to field differences in crop stage, natural enemies and the proximity of virus sources. It would therefore be better to monitor vector immigration and the proportion of viruliferous aphids for each individual field. A mathematical model, based upon our results (see Appendix), indicates the number of primary infections that constitutes a risk in fields with negligible predator impact and in fields with high predator impact on vector establishment.

The calculations with the elementary model formulated in the appendix show that many primary infections can be tolerated in a field where natural enemies are likely to prevent the establishment of vector populations. In fields in which natural enemy impact is likely to be low, only few infections can be tolerated. It might not be feasible to monitor primary infections by capturing aphids and testing for infectivity in such fields, due to the difficulty of detecting the quite low numbers of viruliferous vectors per ha that pose a risk if predators are ineffective. An estimation procedure for how conducive fields are to vector establishment and the spread of virus seems, in view of the above, to be a useful component of warning systems for beet yellowing viruses. The measurement of the relative rate of population increase by two subsequent vector samples in the crop, as advocated for cereal aphids by Entwistle \& Dixon (1986), might provide a feasible method for obtaining such a measure of conduciveness. 


\section{Acknowledgements}

We thank the staff of the experimental farms 'de Minderhoudhoeve' and 'de Bouwing' for technical assistance and Hans van den Heuvel and Walter Rossing for comments on preliminary versions of this paper. Professor Rudy Rabbinge supported the work throughout. Last but not least, helpful comments of the editor and referees on the manuscript are gratefully acknowledged.

\section{Appendix}

Damage is assumed to be proportional to the proportion of infected plants. For low incidences of infection, this proportion is simply the product of the number of patches and the number of infected plants per patch. One plant in a patch is the primarily-infected one. The others are secondarily infected. The number of secondary infections is for simplicity assumed to be the same for all patches. The incidence is then:

$$
i=\frac{p s}{n}
$$

Here $i$ is incidence of infected plants. $p$ over $n$ is the incidence of primary infections, with $p$ being the density or total number of primary infections in a field and $n$ being the density or total number of sugar beet plants in the field. $p$ and $n$ have the same dimension. $s$ is the total number of infected plants per patch, i.e. the total number of infected plants descending from a single primary infection if there would be no overlap between patches. $i$ and $s$ are dimensionless numbers. Eqn 1 is only correct at low incidences of infection. At high incidences, patch overlap must be taken into account. A good approximation for randomly distributed patches is obtained with the expression below (Gregory, 1984; Justesen \& Tammes, 1960):

$$
i=1-\exp \left(-\frac{p s}{n}\right)
$$

Now the total number of infected plants in a patch, $s$, depends on the date of primary infection (Fig. 1A). Equations relating the number of infected plants per patch to primary infection date were derived from the field data by linear regression of $s$ on $t$, the date of primary infection:

Expts 1 and 2; poor vector establishment; large impact of predators:

$$
{ }^{10} \log (s)=4.74-0.0201 t \quad \widehat{\sigma_{R}}=0.14 \quad \mathrm{r}^{2}=0.87
$$

Expt 3; good vector establishment; small impact of predators:

$$
{ }^{10} \log (s)=-13.4+0.244 t-0.000884 t^{2} \quad \widehat{\sigma}_{R}=0.0026 \quad \mathrm{r}^{2}=0.996
$$

In the above equations, $\widehat{\sigma}_{\mathrm{R}}$ is the square root of the residual variance around the regression line. The maximum incidence of primary infections is obtained by substituting either Eqn 3 or 4 in Eqn 2 and solving $p$ from the resulting expressions for chosen values of $t$ and $i$. Results for fields with large (Eqn 3) and small predator impact (Eqn 4) are given in Fig. 8 for three final incidences of infection $(i): 0.05,0.10$ and 0.25 .

\section{References}

Adams, J. R. \& van Emden, H. F. (1972). The biological properties of aphids and their host plant relationships. In Aphid Technology pp. 47-104. Ed. H. F. van Emden. London: Academic Press. 
Baker, P. F. (1960). Aphid behaviour on healthy and on yellows virus-infected sugar beet. Annals of Applied Biology 48, 384-391.

Barel, C. J. A. (1975). Vergelingsziekte in suikerbieten. Bedrijfsontwikkeling 6, 264-268.

Barel, C. J. A. \& Dudok van Heel, E. L. (1978). De waarschuwingsdienst voor de vergelingsziekte in suikerbieten. Gewasbescherming 9, 41-46.

Bar-Joseph, M., Garnsey, S. M. \& Gonsalvez, D. (1979). The closteroviruses: a distinct group of elongated plant viruses. Advances in Virus Research 25, 93-168.

Bennett, C. W. (1960). Sugarbeet yellows disease in the United States. United States Department of Agriculture, Agricultural Research Service Technical Bulletin 1218.

Björling, K. (1952). On the significance of different vectors of sugar beet yellows. Acta Agriculturae Scandinavica II 3, 258-278.

Björling, K. (1961). Stability of strains of beet yellows virus and influence of host genotype on the symptoms. Socker Handlingar II 17, 1-13.

Björling, K. (1963). Effects of different modes of vector inoculation on symptoms and yield reduction by beet yellows virus. Socker Handlingar II 19, 1-23.

Björling, K. \& Nilsson, B. (1966). Observations on host range and vector relationships of beet mild yellowing virus. Socker Handlingar II 21, 1-14.

Björling, K., Lihnell, D. \& Ossiannilsson, F. (1951). Marking viruliferous aphids with radioactive phosphorus. Acta Agriculturae Scandinavica 1, 301-317.

Björling, K. \& Möllerström, G. (1974). Incidence and importance of beet yellowing viruses in Sweden, 1946 to 1973. Socker Handlingar 26, 1-14.

Dewar, A. M. (1988). Chemical Control. In Virus yellows monograph, pp. 55-67. Brussels: IIRB (International Institute for Sugar Beet Research).

Dixon, A. F. G. (1985). Aphid ecology. Glasgow: Blackie.

Duffus, J. E. (1973). The yellowing virus diseases of beet. Advances in Virus Research 18, 347-386.

Entwistle, J. C. \& Dixon, A. F. G. (1986). Short-term forecasting of peak population density of the grain aphid (Sitobion avenae) on wheat. Annals of Applied Biology 109, 215-222.

Entwistle, J. C. \& Dixon, A. F. G. (1989). The effect of augmenting grain aphid (Sitobion avenae) numbers in a field of winter wheat in spring on the aphid's abundance in summer and its relevance to the forecasting of outbreaks. Annals of Applied Biology 114, 397-408.

Frazer, B. D. (1977). Plant virus epidemiology and computer simulation of aphid populations. In Aphids as virus vectors, pp. 413-431. Eds K. F. Harris and K. Maramorosch. New York: Academic Press.

Gildow, F. E. (1980). Increased production of alatae by aphids reared on oats infected with barley yellow dwarf virus. Annals of the Entomological Society of America 73, 343-347.

Gregory, P. H. (1948). The multiple-infection transformation. Annals of Applied Biology 35, 412417.

Hall, A. E. \& Loomis, R. S. (1972a). An explanation for the difference in photosynthetic capabilities of healthy and beet yellows virus-infected sugar beets (Beta vulgaris L.). Plant Physiology 50, 576580 .

Hall, A. E. \& Loomis, R. S. (1972b). Photosynthesis and respiration by healthy and beet yellows virus-infected sugarbeets (Beta vulgaris L.). Crop Science 12, 566-571.

Häni, A. (1979). Die Vergilbungskrankheit bei Zuckerrüben in der Schweiz. Mitteilungen für die Schweizerische Landwirtschaft 27, 15-21.

Harrington, R., Dewar, A. M. \& George, B. (1989). Forecasting the incidence of virus yellows in sugar beet in England. Annals of Applied Biology 114, 459-469.

Heathcote, G. D. (1963). The effect of coccinellids on aphids infesting insecticide-treated sugar beet. Plant Pathology 12, 80-83.

Heathcote, G. D. (1966). The time of flight and the relative importance of Myzus persicae (Sulz.) and Aphis fabae (Scop.) in relation to the incidence of beet yellows as shown by trap catches at Rothamsted and Broom's Barn. Bulletin of Entomological Research 56, 473-480.

Heathcote, G. D. (1974). Aphids caught on sticky traps in eastern England in relation to the spread of yellowing viruses of sugar-beet. Bulletin of Entomological Research 64, 669-676. 
Smith, H. G. \& Hallsworth, P. B. (1990). The effects of yellowing viruses on yield of sugar beet in field trials, 1985 and 1987. Annals of Applied Biology 116, 503-511.

Smith, H. G. \& Hinckes, J. A. (1987). Studies of the distribution of yellowing viruses in the sugar beet root crop from 1981 to 1984. Plant Pathology 36, 125-134.

Sylvester, E. S. (1956). Beet yellows virus transmission by the green peach aphid. Journal of Economic Entomology 49, 789-800.

Thielemann, R. \& Nagi, A. (1977). Neuere Erfahrungen zum Vorkommen Zweier Vergilbungsviren an Zuckerrüben in der Bundesrepublik Deutschland, zur Bedeutung der Vektoren und der Ertragsverluste. Zeitschrift für Pflanzenkrankheiten und Pflanzenschutz 86, 161-168.

Thielemann, R. \& Nagi, A. (1979). Welche Bedeutung haben die zur 'Aphis fabae-Gruppe' gehörenden Blattlausstämme fur die Übertragung des schwachen Vergilbungsvirus auf Beta-Ruben? Zeitschrift für Pflanzenkrankheiten und Pflanzenschutz 86, 161-168.

Thresh, J. M. (1983). Progress curves of plant virus disease. Advances in Applied Biology 8, 1-85.

Van der Werf, W., Bonnier, F. \& Peters, D. (1989a). Retrospective estimation of the date of infection with beet yellowing viruses in sugar-beet under field conditions. Netherlands Journal of Plant Pathology 95, 327-341.

Van der Werf, W., Kempenaar, C. \& Peters, D. (1989b). The incubation period of beet yellowing viruses in sugar-beet under field conditions. Netherlands Journal of Plant Pathology 95, 241-258.

Watson, M. A. \& Healy, M. J. R. (1953). The spread of beet yellows and beet mosaic viruses in the sugar-beet root crop II. The effect of aphid numbers on disease incidence. Annals of Applied Biology 40, 1-37.

Watson, M. A. \& Heathcote, G. D. (1966). The use of sticky traps and the relation to their catches to the spread of viruses in crops. Report of the Rothamsted Experimental Station for 1965, pp. 292300 .

Watson, M. A., Watson, D. J. \& Hull, R. (1946). Factors affecting the loss of yield of sugar beet caused by beet yellows virus. I. Rate and date of infection; date of sowing and harvesting. Journal of Agricultural Sciences, Cambridge 36, 151-166.

Watson, M. A., Heathcote, G. D., Lauckner, F. B. \& Sowray, P. A. (1975). The use of weather data and counts of aphids in the field to predict the incidence of yellowing viruses of sugar-beet crops in England in relation to the use of insecticides. Annals of Applied Biology 81, 181-198.

Watson, M. A., Hull, R., Blencowe, J. W. \& Hamlyn, B. M. G. (1951). The spread of beet yellows and beet mosaic viruses in the sugar beet root crop. Annals of Applied Biology 38, 743-764.

Williams, C. T. (1986). The role of the host plant in the population dynamics of Myzus persicae on sugar beet. Report of the Rothamsted Experimental Station for 1985, part I, pp. 46-47.

Wratten, S. D. \& Pearson, J. (1982). Predation of sugarbeet aphids in New Zealand. Annals of Applied Biology 101, 178-181.

(Received 12 July 1990) 